\title{
HIGH-TEMPERATURE OXIDATION AND DESTRUCTION OF METAL FILAMENTS IN AIR
}

\author{
S.G. ORLOVSKAYA, M.S. SHKOROPADO, F.F. KARIMOVA
}

PACS 536.46. Nr; 662.612.Pa (C) 2011
I.I. Mechnikov's Odessa National University, Odessa, Ukraine

(Dvoryanskaya, 2, Odessa 65082, Ukraine; e-mail: svetor@ rambler. ru)

\begin{abstract}
The high-temperature oxidation and the thermal destruction of electrically heated tungsten and molybdenum filaments in air are studied experimentally. The temperature histories of filaments are obtained, and the successive stages of oxidation are defined. It is shown that the phase transition points of oxides determine the limits of these stages. The filament destruction conditions are established: the temperature in and the diameter of the filament central zone, the electric current corresponding to the filament failure, as well as the burning time. The behavior of oxide particles in an electric field is studied.
\end{abstract}

\section{Introduction}

The phenomenon of the metal wire electric explosion (WEE) has been studied for a long time [1]. The current numerous investigations are stimulated by promising perspectives and applications - from the formation of metal nanoparticles to controlled nuclear fusion $[2,3]$. A large variety of effects occurring during the electric explosion is caused by a wide range of possible operating parameters (electric power, heating duration, temperature, gas pressure, and composition). Nevertheless, the modern WEE investigations mainly deal with fast (microseconds) and superfast (nanoseconds) electric heating impulses in vacuum or inert atmosphere. The thermal explosion of a wire as a result of its high temperature oxidation is explored quite insufficiently. First of all, there is a lack of the experimental data on the thermal destruction of heavily oxidized tungsten and molybdenum filaments. At the same time, the investigations of such a phenomenon are of great interest in view of the unique catalytic, electrochromic, and gas-sensing properties of tungsten and molybdenum oxides. Nowadays, the numerous studies are aimed at the elaboration of effective methods of production of $\mathrm{WO}_{3}$ and $\mathrm{MoO}_{3}$ films. A promising way to the production of refractory metal oxide films is the "hot-filament" method, which consists in the controlled resistive heating of a metal filament in the oxidizing atmosphere [4]. Here, we study the main features of the high-temperature oxidation and the thermal destruction of refractory metal filaments with a special attention to ignition conditions. It is well known that an oxide scale affects significantly the high-temperature heat transfer and the oxidation kinetics of metals. In addition, the tungsten and molybdenum trioxides have low melting points and high vaporization rates at relatively low temperatures. So, the critical conditions of the ignition of these metals are mainly defined by the melting and the evaporation of an oxide scale [5].

\section{Results and Discussion}

To study the high-temperature oxidation and the thermal explosion of metal filaments, a special experimental setup is constructed, and diagnostics methods are elaborated. The metal filament is connected to copper current-carrying electrodes and is heated electrically by a DC stabilized power supply. To define the mean filament temperatures, the voltage drop is measured and the specific resistance is calculated for successive moments of time. The temperature is calculated according to the formula

$T=\left(\frac{R}{R_{\mathrm{r}}}-1\right)\left(\frac{1}{\gamma}-T_{0}\right)+\frac{R}{R_{\mathrm{r}}} T_{r}$,

where $T$ is the current value of the filament mean temperature, $\mathrm{K} ; R$ is the current value of the filament resistivity, Ohm; $R_{\mathrm{r}}$ is the filament resistivity at room temperature, Ohm; $T_{\mathrm{r}}$ is room temperature, $\mathrm{K} ; \gamma$ is the resistivity temperature factor, $\mathrm{K}^{-1} ; T_{0}=273 \mathrm{~K}$.

At the same time, the temperature in the central zone of the sample is measured by a telescopic disappearing filament pyrometer EOP-66. In order to fix the oxide scale growth and the evaporation, the filament is shooting by a video camera continuously. The temperature profile along the filament is defined by the original method of relative brightness pyrometry [6]: the glowing filament is imaged by a Canon-350D camera through a narrow-band optical filter, and the digital images are processed with MatLab 7.0. The brightness distribution is converted to the temperature field according to the 


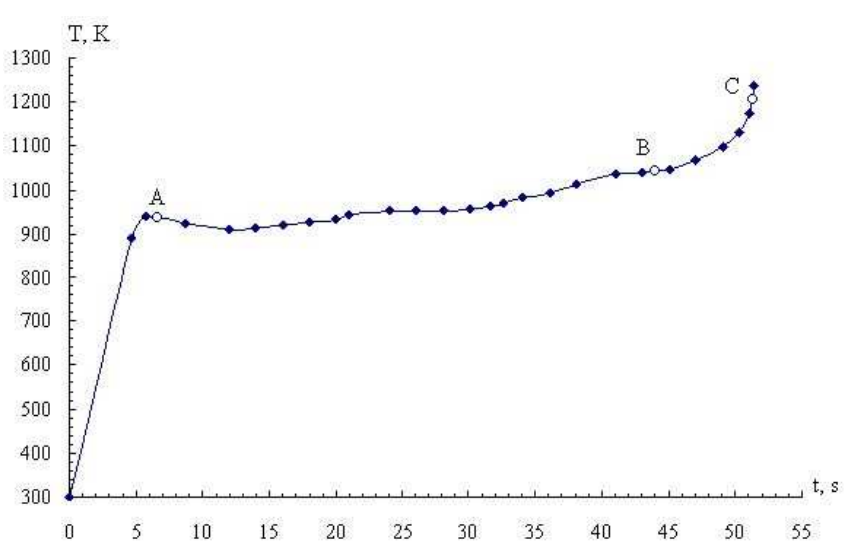

Fig. 1. Molybdenum filament temperature history; $d=200 \mu \mathrm{m}$, $L=100 \mathrm{~mm}, I=4 \mathrm{~A}, T_{\mathrm{r}}=293 \mathrm{~K}$

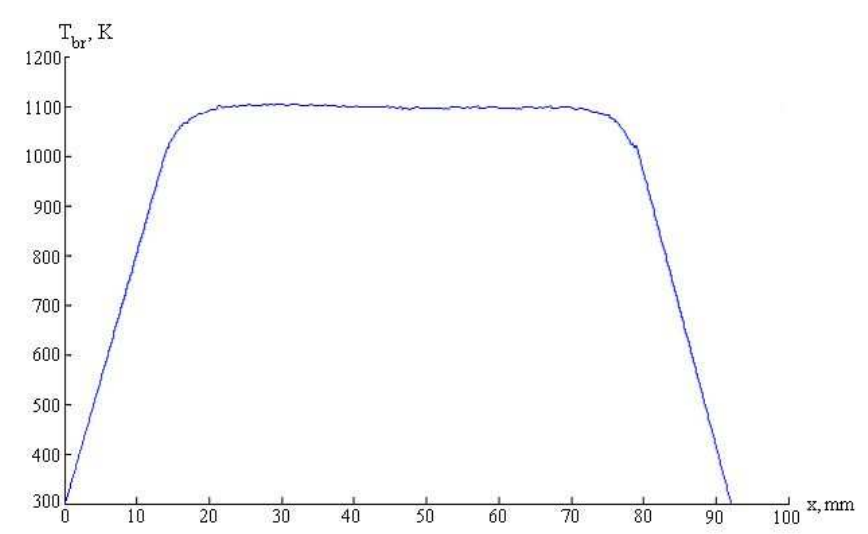

Fig. 2. Brightness temperature distribution along a molybdenum filament; $d=200 \mu \mathrm{m}, L=100 \mathrm{~mm}, I=4 \mathrm{~A}, T_{\mathrm{r}}=293 \mathrm{~K}$

Wien approximation:

$\frac{1}{T_{\mathrm{br}}(x)}=\frac{1}{T_{\mathrm{br}, c}}+\frac{\lambda}{C_{2}} \ln \left[\frac{S_{c}}{S(x)}\right]$.

Here, $T_{\mathrm{br}}(x)$ is the brightness temperature at the point $x, \mathrm{~K} ; T_{\mathrm{br}, c}$ is the reference value of brightness temperature measured by an optical pyrometer at the center of the filament, $S(x)$ is the filament image intensity at the point $x, S_{c}$ is one at the reference point, $\lambda$ is the narrowband optical filter wavelength, $\mu \mathrm{m} ; C_{2}=14387 \mu \mathrm{m} \cdot \mathrm{K}$. The temperature profiles obtained are analyzed, and the correlation between the maximum filament temperature and the average one is obtained.

To study the electric properties of oxide particles formed during the evaporation and the explosion, the filament was placed between the capacitor plates, and a voltage (200-1000 V) was applied between the plates (the interplate distance is $50 \mathrm{~mm}$ ).

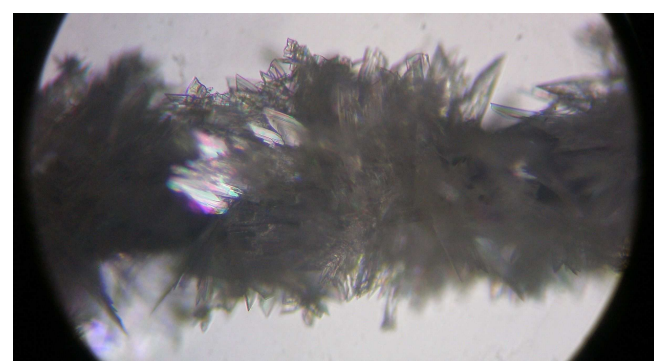

Fig. 3. Crystals of $\mathrm{MoO}_{3}$ above the scale (x110)

The molybdenum filaments with an initial diameter of about $d=200 \mu \mathrm{m}$, tungsten filaments with three initial diameters $(100,200$, and $300 \mu \mathrm{m})$ and $L=100 \mathrm{~mm}$ in length are heated electrically till the thermal destruction. The temperature histories are obtained and analyzed. In Fig. 1, the temperature history of a molybdenum filament is presented.

The analysis of the molybdenum filament temperature history shows that, after switching-on the current, the temperature of a filament rises abruptly to some quasistationary value (point A). This stage corresponds to the inert resistive heating of the filament and the formation of an initial oxide film. The next quasistationary stage describes the parabolic oxide scale growth and its successive melting and evaporation. During stage (B-C), the temperature distribution along the filament is uniform except the ends, where the temperature decreases sharply (Fig. 2).

The oxide scale is covered by a great number of bushlike crystals (Fig. 3). When the temperature exceeds $1170 \mathrm{~K}$, the oxide evaporation rate is higher than the oxide scale growth rate. So, the protective layer disappears quickly, and the oxidation rate increases dramatically. As a result, the filament burns out quickly. As a rule, it looks like a small explosion with the dusty plasma formation. Sometimes, it is just a small smoke plume.

It is found that the oxide melting and the evaporation affect significantly the critical parameters and the filament destruction mechanism. Thus, the molybdenum oxide melting and the subsequent diffusion inside the metal through grain boundaries led to the filament explosive disintegration at the oxide boiling point. The instantaneous burning of metal particles results in the dusty plasma formation. The luminous dusty cloud dynamics is studied by the digital imaging. The images obtained were processed by the Image Processing Toolbox of MatLab 7.0. It is found that the dusty plasma maximum volume lifetime is about $0.1 \mathrm{~s}$. The studies of combustion products with an optical microscope shows that molybdenum oxide particles form, as a rule, fila- 


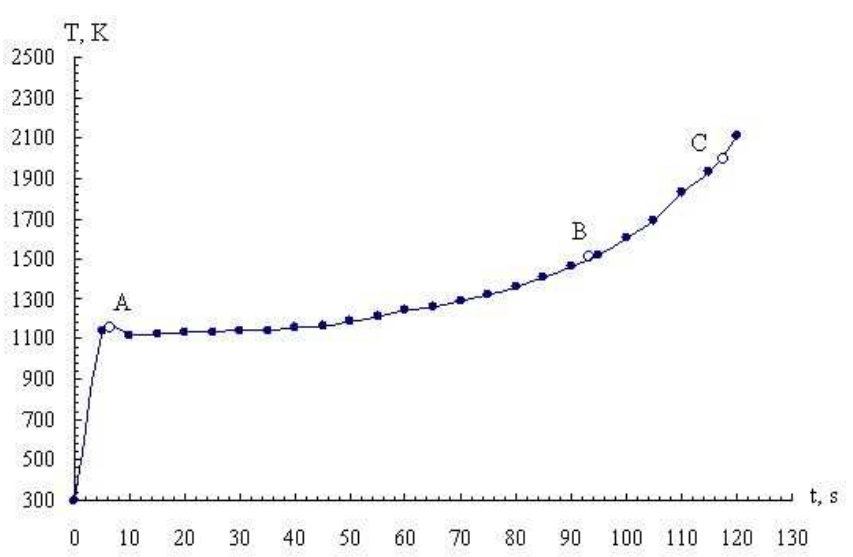

Fig. 4. Tungsten filament temperature history; $d=300 \mu \mathrm{m}, L=$ $100 \mathrm{~mm}, I=7.5 \mathrm{~A}, T_{\mathrm{r}}=293 \mathrm{~K}$

mentary aggregates (the diameter is about one hundred microns, and the length measured is up to $10 \mathrm{~mm}$ ). It is well known that such filament structures are formed when charged particles aggregate. In fact, the smoke of oxide particles curves to the negatively charged plate of the capacitor.

The temperature history of the non-stationary heating of a tungsten sample (Fig. 4) has some differences. First of all, the quasistationary temperature is higher, its duration is distinctly longer (part A-B) and the preignition temperature rise is smoother in comparison with that on the molybdenum curve (part B-C). The heating current destruction values which delimit the stationary oxidation process and the non-stationary one are determined, as well as the filament ignition temperatures (Table). To investigate the oxide scale features, the oxidized filaments are studied microscopically before the ignition and after it. It is found that the sample temperature history influences greatly the oxide scale thickness and the structure and, as a result, the filament destruction characteristics.

The filament thermal destruction characteristics

\begin{tabular}{|c|c|c|c|c|}
\hline Filament & \multicolumn{2}{|c|}{$\begin{array}{c}\mathrm{W} \\
L=100 \mathrm{~mm} \\
d=300 \mu \mathrm{m}\end{array}$} & \multicolumn{2}{|c|}{$\begin{aligned} \text { Mo } & \\
L= & 100 \mathrm{~mm} \\
d= & 200 \mu \mathrm{m}\end{aligned}$} \\
\hline Oxides & $\mathrm{WO}_{2}$ & $\mathrm{WO}_{3}$ & $\mathrm{MoO}_{2}$ & $\mathrm{MoO}_{3}$ \\
\hline Melting point, $\mathrm{K}$ & 1800 & 1743 & 1300 & 1074 \\
\hline Boiling point, $\mathrm{K}$ & - & 2120 & - & 1428 \\
\hline$T_{\text {dest }}, \mathrm{K}$ (mean) & \multicolumn{2}{|c|}{1855} & \multicolumn{2}{|c|}{1250} \\
\hline$T_{\text {dest }}, \mathrm{K}$ (centre) & \multicolumn{2}{|c|}{2100} & \multicolumn{2}{|c|}{1400} \\
\hline $\mathrm{I}_{\text {dest }}, \mathrm{A}$ & \multicolumn{2}{|c|}{7} & \multicolumn{2}{|c|}{4} \\
\hline $\mathrm{d}_{\mathrm{dest}}, \mu \mathrm{m}$ & \multicolumn{2}{|c|}{200} & \multicolumn{2}{|c|}{160} \\
\hline$\frac{d_{\text {dest }}}{d}$ & \multicolumn{2}{|c|}{0.67} & \multicolumn{2}{|c|}{0.8} \\
\hline
\end{tabular}

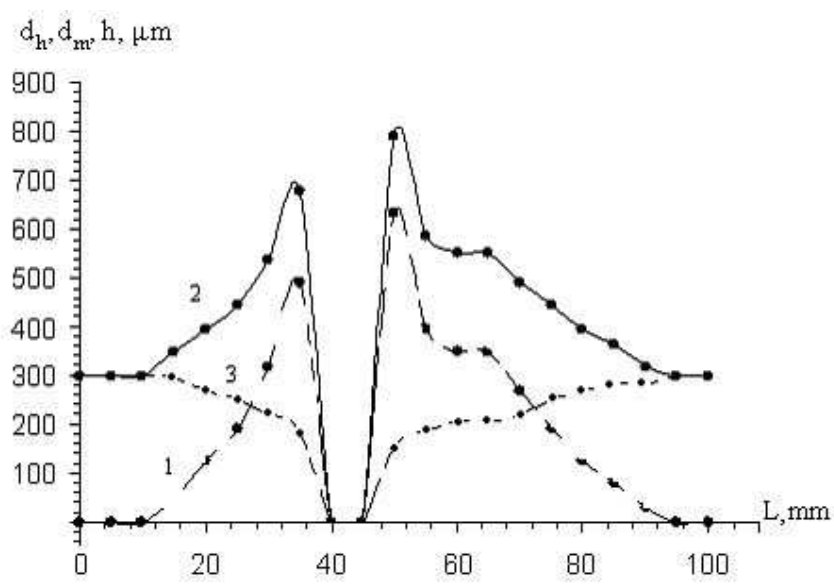

Fig. 5. Failed tungsten filament diameter, non-oxide metal core diameter, and oxide scale thickness distributions; $d=300 \mu \mathrm{m}$, $L=100 \mathrm{~mm}, I=6.87 \mathrm{~A}, T=1855 \mathrm{~K} .1-h, 2-d_{h}, 3-d_{m}$

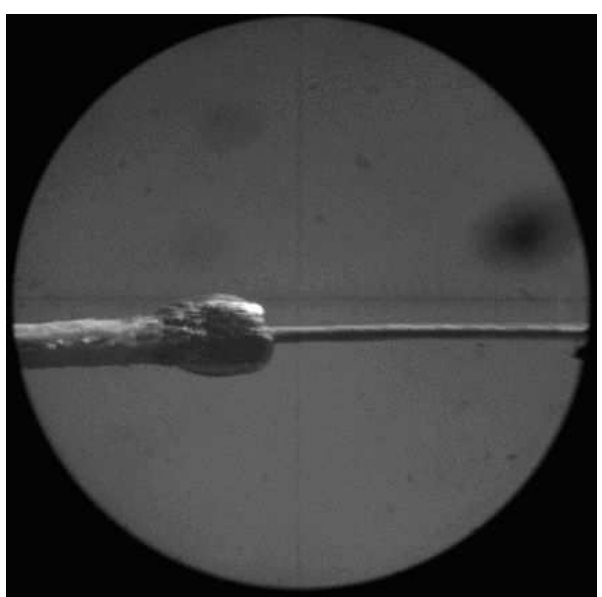

Fig. 6. Image of a failed tungsten filament $(\times 90)$

The destruction of molybdenum and tungsten filaments have some peculiarities: in case of molybdenum, the filament surface at the failure time moment is practically oxide-free, and the smoke is formed by dispersed metal combustion products. When a tungsten filament is near to the ignition, the scale is filled with deep cracks, and hot spots appear on the surface. The distributions of oxidized filament diameters $d_{h}$, non-oxidized metal core diameters $d_{m}$, and oxide scale thicknesses $h$ along the failed filament are presented in Fig. 5. A zero-diameter central zone corresponds to the destroyed part of the filament. As shown, the oxidized filament total diameter is twice greater than the initial one. The image of the tungsten filament central zone immediately before the failure is presented in Fig. 6. We can see that a part of the filament is completely oxide-free. 
The oxide evaporation mainly takes place in a relatively narrow region at the center of a tungsten filament as a result of the decomposition of tungsten dioxide at $1800 \mathrm{~K}$ (Fig. 6). The metal layer over scale confirms this mechanism. The oxide particles in the electric field curve to the negative plate of the capacitor, i.e., they are charged positively.

The behavior of oxide particles in an electric field is studied. It is found that the plume of burning products curves to the negative plate of the capacitor. The plume image processing enables us to determine the ratio of the drift speed to the natural convection rate. Under our experimental conditions, we found $V_{d} / V_{n}=0.5$. To find the drift speed, we estimate the natural convection rate according to the formula

$V_{n}=\sqrt{\frac{g \triangle T d}{2 T_{0}}}$,

where $\triangle T$ is the temperature difference between the hot filament and surrounding air, $\mathrm{K} ; d$ is the filament diameter, $\mathrm{cm} ; g$ is the gravity acceleration, $\mathrm{cm} \cdot \mathrm{s}^{-2}$.

In such a way, we found $V_{n}=6.4 \mathrm{~cm} \cdot \mathrm{s}^{-1}$ and correspondingly molybdenum oxide particles drift speed equals $V_{d}=3.2 \mathrm{~cm} \cdot \mathrm{s}^{-1}$. Mobility is defined as the ratio of the field strength $\left(E=120 \mathrm{~V} \cdot \mathrm{cm}^{-1}\right)$ to the drift speed:

$\mu=\frac{E}{V_{d}}, \quad \mu=0.025\left(\mathrm{~V} \cdot \mathrm{s} \cdot \mathrm{cm}^{-2}\right)$.

On the other hand, the particle mobility depends on its diameter $\left(d_{p}\right)$ and electric charge $(Z)$ as

$\mu \sim \frac{Z}{d_{p}}$

As the oxide particles have nearly the same drift speeds, we draw a preliminary conclusion that they are equidimensional.

\section{Conclusions}

Thus, the features of the thermal destruction of heavily oxidized tungsten and molybdenum filaments are stud- ied; the corresponding parameters are defined. The data obtained are of significant interest from the point of view of the production of metal oxide films. The possibility of the oxide directional coating by applying the electric field is demonstrated.

1. W.G. Chace, Phys. Today 17, No. 8, 19 (1964).

2. S.L. Yap, Y.S. Lee, W.H. Tay, and C.S. Wong, in Proceedings of the Intern. Workshop on Plasma Computations and Applications (2008), p. 60.

3. S. Naoyuki, N. Masayoshi, T. Yusuke, and A. Hidenori, Jap. J. of Appl. Phys. 39, 6051 (2000).

4. F. Paulo Rouxinol, B. Claudio Trasferetti, R. Landers, and M.A. Bica de Moraes, J. Braz. Chem. Soc. 15 (2004).

5. S.G. Orlovskaya, F.F. Karimova, and M.S. Shkoropado, in Proceedings of the 7-th World Conference on Experimental Heat Transfer, Fluid Mechanics and Thermodynamics (ExHFT-7, Krakow, 2009), p. 2129.

6. F.F. Karimova, and S.G. Orlovskaya, The Determination Method of Local Brightness Temperature and Temperature Distribution along the Hot Body Surface, Patent of Ukraine No.44416, 12.10.2009, Bull.(19).

Received 19.01.11

ВИСОКОТЕМПЕРАТУРНЕ ОКИСЛЕННЯ І ТЕРМІЧНЕ РУЙНУВАННЯ МЕТАЛЕВИХ ДРОТИКІВ У ПОВІТРІ

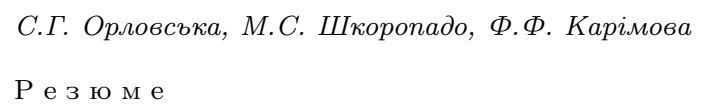

Експериментально вивчено високотемпературне окислення i термічне руйнування вольфрамових та молібденових дротиків, що нагріваються електричним струмом в повітрі. Отримано часові залежності температури дротиків, встановлено послідовні стадії процесу окислення. Показано, що точки фазових переходів оксидів металів розмежовують ці стадії. Визначено параметри руйнування: струм, температура і діаметр у місці перегорання. Вивчено поведінку частинок оксидів в електричному полі. 